\title{
Fluctuating Heat and Mass Transfer on Unsteady MHD Free Convection Flow of Radiating and Reacting Fluid past a Vertical Porous Plate in Slip- Flow Regime
}

\author{
K. D. Singh ${ }^{1}$ and R. Kumar ${ }^{2 \dagger}$ \\ ${ }^{1}$ Department of Mathematics (ICDEOL), H.P. University, Shimla-171 005, India \\ ${ }^{2}$ Department of Mathematics, Govt. College For Girls ( RKMV), Longwood, Shimla-171 001, India \\ †Corresponding Author Email: rakesh.lect@gmail.com
}

(Received December 1, 2009; accepted September 23, 2010)

\begin{abstract}
In this paper, an analytical study on unsteady MHD free convective viscous incompressible flow of electricallyconducting fluid with periodic heat and mass transfer past an infinite vertical porous flat plate in slip flow regime is presented. A uniform magnetic field perpendicular to the plate is applied. The effects of thermal radiation and chemical reaction are included. The effects of flow parameters and thermo physical properties on the flow, temperature and concentration fields across the boundary layer are investigated. The forms of the wall shear stress, Nusselt number and Sherwood number are derived. The results are shown in figures and tables followed by a quantitative discussion.
\end{abstract}

Keywords: MHD, Free convection, Thermal radiation, Chemical reaction, Slip-flow regime.

\section{INTRODUCTION}

Process involving coupled heat and mass transfer occur frequently in nature. It occurs not only due to temperature difference, but also due to concentration difference or the combination of these two. The effect of chemical reaction depends on whether the reaction is heterogeneous or homogeneous. In nature, the presence of pure air or water is not possible. Some foreign mass may be present either naturally or mixed with air or water. The presence of foreign mass in air or water causes some kind of chemical reaction. The study of such type of chemical reaction processes is useful for improving a number of chemical technologies, such as food processing, polymer production and manufacturing of ceramics or glassware. Chambre and Young (1958) analyzed the effect of homogeneous first order chemical reactions in the neighborhood of a flat plate for destructive and generative reactions. Das et al. (1994) studied the effect of first order reaction on the flow past an impulsively started infinite vertical plate with uniform heat flux and mass transfer. Anjalidevi and Kandasamy (2000) investigated the effect of chemical reaction on the flow in the presence of heat transfer and magnetic field. Muthucumaraswamy and Ganesan (2001) studied the effect of chemical reaction on unsteady flow past an impulsively started infinite vertical plate. Raptis and Perdikis (2006) studied numerically the steady two-dimensional flow in the presence of chemical reaction over a non-linearly semiinfinite stretching sheet. Moreover chemical reaction effects on heat and mass transfer laminar boundary layer flow have been studied by several scholars e.g. Chamkha (2003), Kandasamy et al. (2005), Afify (2004), Takhar et al. (2000), and Mansour et al. (2008) etc.

Radiative convective flows are encountered in countless industrial and environment processes e.g. heating and cooling chambers, fossil fuel combustion energy processes, evaporation from large open water reservoirs, astrophysical flows, solar power technology and space vehicle reentry. Radiative heat and mass transfer play an important role in manufacturing industries for the design of reliable equipment. Nuclear power plants, gas turbines and various propulsion devices for air craft, missiles, satellites and space vehicles are examples of such engineering applications. Loganathan et al. (2008) studied first order chemical reaction on moving vertical plate for optically thin gray gas. Raptis and Perdikis (2003) investigated the effects of thermal radiation on a moving vertical plate in the presence of mass diffusion. Sharma et al. (2008) analyzed radiation effects on steady free convective flow along a moving vertical porous plate in the presence of magnetic field and heat source / sink.

In many practical applications, the particle adjacent to a solid surface no longer takes the velocity of the surface. The particle has a finite tangential velocity; it 'slips' along the surface. The flow regime is called slip-flow 
regime and this effect cannot be neglected. Using these assumptions Sharma and Chaudhary (2003) and Sharma and Sharma (2004) have also discussed the free convection flow past a vertical plate in slip-flow regime and also discussed its various applications for engineering purpose. Numerous authors have studied free convection problems in slip-flow regime e.g. Sharma (2005), Mansour et al. (2007), Jain and Gupta (2007) and Jothimani and Anjalidevi (2001) etc.

The objective of the present paper is to investigate the effects of radiation and first order chemical reaction on an unsteady MHD free convective heat and mass transfer flow past a vertical porous flat plate in slipflow regime when suction velocity oscillates in time about a non-zero constant mean because in actual practice temperature, species concentration and suction velocity may not always be uniform.

\section{MATHEMATICAL ANALYSIS}

We consider an unsteady MHD free convective flow of a viscous, incompressible, electrically conducting, thermally radiating and chemically reacting fluid past an infinite vertical porous flat plate in slip-flow regime with periodic temperature and concentration. The suction velocity is assumed to be of the form

$v^{*}=-v_{0}^{*}\left(1+\in A e^{i \omega^{*} t^{*}}\right)$,

where $v_{0}^{*}$ is the mean suction velocity, $\omega^{*}$ is the

frequency of oscillation, $t^{*}$ is the time, $A$ is a positive real constant and $\in$ is small such that $A \in<<1$.We introduce a co-ordinate system with wall lying vertically in $x^{*}-y^{*}$ plane. The $x^{*}$-axis is taken in vertical upward direction along the vertical porous plate and $y^{*}$-axis is taken normal to the plate. A magnetic field $B_{0}$ of uniform strength is introduced normal to the plane of the plate. Since the plate is considered infinite in $x^{*}$ - direction, hence all physical quantities will be independent of $x^{*}$. Under these assumptions the physical variables are functions of $y^{*}$ and $t^{*}$ only.

We further assume that (i) the magnetic Reynolds number is small so that the induced magnetic field is negligible in comparison to the applied magnetic field, (ii) the fluid is considered to be gray; absorbing emitting radiation but a non-scattering medium, (iii) viscous dissipation and Joule heating terms are neglected as small velocity usually encountered in free convection flows, (iv) no external electric field is applied and effect of polarization of ionized fluid is negligible, therefore electric field is assumed to be zero, (v) there exists a first order chemical reaction between the fluid and species concentration, (vi) the level of species concentration is very low so that the heat generated during chemical reaction can be neglected.

Using the Boussinesq and boundary - layer approximation, the governing equations for this problem can be written as follows:

$$
\begin{gathered}
\frac{\partial u^{*}}{\partial t^{*}}-v_{0}^{*}\left(1+\in A e^{i \omega^{*} t^{*}}\right) \frac{\partial u^{*}}{\partial y^{*}}=v \frac{\partial^{2} u^{*}}{\partial y^{* 2}} \\
+g \beta\left(T^{*}-T_{\infty}^{*}\right)+g \beta_{c}\left(C^{*}-C_{\infty}^{*}\right)-\frac{\sigma B_{0}^{2}}{\rho} u^{*} \\
\rho C_{P}\left(\frac{\partial T^{*}}{\partial t^{*}}-v_{0}^{*}\left(1+\in A e^{i \omega^{*} t^{*}}\right) \frac{\partial T^{*}}{\partial y^{*}}\right)=k \frac{\partial^{2} T^{*}}{\partial y^{* 2}} \\
-\frac{\partial q_{r}^{*}}{\partial y^{*}} \\
\frac{\partial C^{*}}{\partial t^{*}}-v_{0}^{*}\left(1+\in A e^{i \omega^{*} t^{*}}\right) \frac{\partial C^{*}}{\partial y^{*}}=D \frac{\partial^{2} C^{*}}{\partial y^{* 2}}, \\
-K_{1}\left(C^{*}-C_{\infty}^{*}\right)
\end{gathered}
$$

where $g, T^{*}, C^{*}, B_{0}, D, \sigma, k, C_{P}, v, \rho, \beta, \beta_{c}, q^{*}$ and $K_{1}$ are acceleration due to gravity, fluid temperature, species concentration, magnetic field, chemical molecular diffusivity, electrical conductivity, thermal conductivity, specific heat at constant pressure, kinematic viscosity, density, coefficient of volume expansion for heat transfer, volumetric coefficient of expansion with species concentration, radiative heat flux and chemical reaction parameter, respectively.

The boundary conditions of the problem are

$$
\begin{aligned}
& \left.u^{*}=L^{*}\left(\frac{\partial u^{*}}{\partial y^{*}}\right), T^{*}=T_{0}^{*}+\in\left(T_{0}^{*}-T_{\infty}^{*}\right) e^{i \omega^{*} t^{*}}\right\} \text { at } y=0 \\
& C^{*}=C_{0}^{*}+\in\left(C_{0}^{*}-C_{\infty}^{*}\right) e^{i \omega^{*} t^{*}} \\
& u^{*} \rightarrow 0, T^{*} \rightarrow T_{\infty}^{*}, C^{*} \rightarrow C_{\infty}^{*} \text { as } y \rightarrow \infty
\end{aligned}
$$

where $T_{0}^{*}$ and $T_{\infty}^{*}$ are the temperature at the wall and at infinity, $C_{0}^{*}$ and $C_{\infty}^{*}$ are the species concentration at the wall and at infinity, respectively.

The local radiant for the case of an optically thin gray gas is expressed by

$$
\frac{\partial q_{r}^{*}}{\partial y^{*}}=-4 a^{*} \sigma^{*}\left(T_{\infty}^{*^{4}}-T^{*^{4}}\right),
$$

where $a^{*}$ is the mean absorption coefficient and $\sigma^{*}$ is Stefan - Boltzmann constant.

We assume that the temperature differences with in the flow are sufficiently small such that $T^{*^{4}}$ may be expressed as a linear function of the temperature. This is accomplished by expanding $T^{* 4}$ in a Taylor series about $T_{\infty}^{*}$ and neglecting higher-order terms, thus

$$
T^{*^{4}} \cong 4 T_{\infty}^{*^{3}} T^{*}-3 T_{\infty}^{*^{4}} \text {. }
$$

By using Eqs. (5) and (6), Eq. (2) reduces to

$$
\begin{gathered}
\rho C_{P}\left(\frac{\partial T^{*}}{\partial t^{*}}-v_{0}^{*}\left(1+\in A e^{i \omega^{*} t^{*}}\right) \frac{\partial T^{*}}{\partial y^{*}}\right)=k \frac{\partial^{2} T^{*}}{\partial y^{* 2}} \\
-16 a^{*} \sigma^{*} T_{\infty}^{* 3}\left(T^{*}-T_{\infty}^{*}\right)
\end{gathered}
$$


K.D. Singh and R. Kumar / JAFM, Vol. 4, No. 4, pp. 101-106, 2011.

Introducing the following non-dimensional parameters

$y=\frac{y^{*} v_{0}^{*}}{v}, t=\frac{t^{*} v_{0}^{*^{2}}}{4 v}, u=\frac{u^{*}}{v_{0}^{*}}, \omega=\frac{4 v \omega^{*}}{v_{0}^{*^{2}}}$,

$\theta=\frac{T^{*}-T_{\infty}^{*}}{T_{0}^{*}-T_{\infty}^{*}}, \phi=\frac{C^{*}-C_{\infty}^{*}}{C_{0}^{*}-C_{\infty}^{*}}$,

$\operatorname{Pr}=\frac{\mu C_{p}}{k}($ Prandtl number $)$

$S c=\frac{v}{D}$ (Schmidt number),

$G r=\frac{\operatorname{vg} \beta\left(T_{0}^{*}-T_{\infty}^{*}\right)}{v_{0}^{*^{3}}}$ (thermal Grashof number),

$h=\frac{v_{0}^{*} L^{*}}{v}($ slip parameter $)$,

$G m=\frac{v g \beta_{c}\left(C_{0}^{*}-C_{\infty}^{*}\right)}{v_{0}^{*^{3}}}$ (mass Grashof number),

$M=\frac{B_{0}}{v_{0}^{*}} \sqrt{\frac{\sigma v}{\rho}}$ (Hartmann number)

$R=\frac{16 a^{*} v^{2} \sigma^{*} T_{\infty}^{*^{3}}}{k v_{0}^{*^{2}}}$ (radiation parameter),

$\gamma=\frac{K_{1} v}{v_{0}^{2}}$ (chemical reaction parameter)

into the Eqs. (1), (3) and (7), we get

$$
\begin{aligned}
& \frac{1}{4} \frac{\partial u}{\partial t}-\left(1+\in A e^{i \omega t}\right) \frac{\partial u}{\partial y}=\frac{\partial^{2} u}{\partial y^{2}}+G r \theta, \\
& +G m \phi-M^{2} u \\
& \frac{1}{4} \frac{\partial \theta}{\partial t}-\left(1+\in A e^{i \omega t}\right) \frac{\partial \theta}{\partial y}=\frac{1}{\operatorname{Pr} \frac{\partial^{2} \theta}{\partial y^{2}}-\frac{R}{\operatorname{Pr}} \theta,} \\
& \frac{1}{4} \frac{\partial \phi}{\partial t}-\left(1+\in A e^{i \omega t}\right) \frac{\partial \phi}{\partial y}=\frac{1}{S c} \frac{\partial^{2} \phi}{\partial y^{2}}-\gamma \phi .
\end{aligned}
$$

The boundary conditions to the problem in dimensionless form are

$$
\left.\begin{array}{l}
u=h \frac{\partial u}{\partial y}, \theta=1+\in e^{i \omega t}, \phi=1+\in e^{i \omega t} \text { at } y=0 \\
u \rightarrow 0, \quad \theta \rightarrow 0, \quad \phi \rightarrow 0 \quad \text { as } y \rightarrow \infty
\end{array}\right\}
$$

\section{SOLUtion OF THE Problem}

Assuming the small amplitude oscillations $(\in<<1)$, we can represent the velocity $u$, temperature $\theta$ and concentration $\phi$ near the plate as follows:

$$
F(y, t)=F_{0}(y)+\in F_{1}(y) e^{i \omega t},
$$

where $F$ stands for $u, \theta$ and $\phi$. Then substituting Eq. (12) into Eqs. (8) to (10) and equating the coefficients of harmonic and non-harmonic terms, we get

$$
\begin{aligned}
& \theta_{0}^{\prime \prime}+\operatorname{Pr} \theta_{0}^{\prime}-R \theta_{0}=0, \\
& \theta_{1}^{\prime \prime}+\operatorname{Pr} \theta_{1}^{\prime}-\left(R+\frac{i \omega \operatorname{Pr}}{4}\right) \theta_{1}=-A \operatorname{Pr} \theta_{0}^{\prime}, \\
& \phi_{0}^{\prime \prime}+S c \phi_{0}^{\prime}-S c \gamma \phi_{0}=0, \\
& \phi_{1}^{\prime \prime}+S c \phi_{1}^{\prime}-S c\left(\gamma+\frac{i \omega}{4}\right) \phi_{1}=-A S c \phi_{0}^{\prime}, \\
& u_{0}^{\prime \prime}+u_{0}^{\prime}-M^{2} u_{0}=-G r \theta_{0}-G m \phi_{0}, \\
& u_{0}^{\prime \prime}+u_{0}^{\prime}-\left(M^{2}+\frac{i \omega}{4}\right) u_{1}=-G r \theta_{1}-G m \phi_{1}, \\
& -A u_{0}^{\prime}
\end{aligned}
$$

The corresponding boundary conditions reduce to

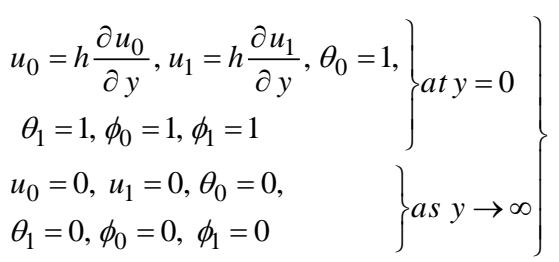

Solving Eqs (13) to (18) under the boundary conditions (19), we get

$$
\begin{aligned}
& \theta_{0}(y)=e^{-n_{1} y}, \\
& \theta_{1}(y)=e^{-n_{2} y}+d_{1}\left(e^{-n_{1} y}-e^{-n_{2} y}\right), \\
& \phi_{0}(y)=e^{-n_{3} y}, \\
& \phi_{1}(y)=e^{-n_{4} y}+d_{2}\left(e^{-n_{3} y}-e^{-n_{4} y}\right), \\
& u_{0}(y)=\frac{d_{3}}{m_{5}}\left(m_{1} e^{-n_{5} y}-m_{5} e^{-n_{1} y}\right) \\
& +\frac{d_{4}}{m_{5}}\left(m_{3} e^{-n_{5} y}-m_{5} e^{-n_{3} y}\right) \\
& u_{1}(y)=d_{5}\left(m_{6} e^{-n_{1} y}-m_{1} e^{-n_{6} y}\right) \\
& +d_{6}\left(m_{2} e^{-n_{6} y}-m_{6} e^{-n_{2} y}\right)+d_{7}\left(m_{6} e^{-n_{3} y}-m_{3} e^{-n_{6} y}\right) \\
& +d_{8}\left(m_{4} e^{-n_{6} y}-m_{6} e^{-n_{4} y}\right)+d_{9}\left(m_{5} e^{-n_{6} y}-m_{6} e^{-n_{5} y}\right),
\end{aligned}
$$

where

$$
\begin{aligned}
& n_{1}=\frac{\operatorname{Pr}+\sqrt{\operatorname{Pr}^{2}+4 R}}{2}, n_{2}=\frac{\operatorname{Pr}+\sqrt{\operatorname{Pr}^{2}+4 R+i \omega \operatorname{Pr}}}{2}, \\
& n_{3}=\frac{S c+\sqrt{S c^{2}+4 \gamma S c}}{2}, \\
& n_{4}=\frac{S c+\sqrt{S c^{2}+4 \gamma S c+i \omega S c}}{2}, n_{5}=\frac{1+\sqrt{1+4 M^{2}}}{2}, \\
& n_{6}=\frac{1+\sqrt{1+4 M^{2}+i \omega}}{2}, m_{1}=h n_{1}+1, \\
& m_{2}=h n_{2}+1, m_{3}=h n_{3}+1, m_{4}=h n_{4}+1, m_{5}=h n_{5}+1 \\
& , m_{6}=h n_{6}+1, d_{1}=\frac{A \operatorname{Pr} n_{1}}{n_{1}^{2}-\operatorname{Pr} n_{1}-\left(R+\frac{i \omega \operatorname{Pr}}{4}\right)},
\end{aligned}
$$


K.D. Singh and R. Kumar / JAFM, Vol. 4, No. 4, pp. 101-106, 2011.

$$
\begin{aligned}
& d_{2}=\frac{A S c n_{3}}{n_{3}^{2}-S c n_{3}-S c\left(\gamma+\frac{i \omega}{4}\right)}, d_{3}=\frac{G r}{n_{1}^{2}-n_{1}-M^{2}}, \\
& d_{4}=\frac{G m}{n_{3}^{2}-n_{3}-M^{2}}, \quad d_{5}=\frac{A d_{3} n_{1}-G r d_{1}}{n_{1}^{2}-n_{1}-\left(M^{2}+\frac{i \omega}{4}\right)}, \\
& d_{6}=\frac{G r\left(1-d_{1}\right)}{n_{2}^{2}-n_{2}-\left(M^{2}+\frac{i \omega}{4}\right)}, \\
& d_{7}=\frac{A d_{4} n_{3}-G m d_{2}}{n_{3}^{2}-n_{3}-\left(M^{2}+\frac{i \omega}{4}\right)}, \\
& d_{8}=\frac{G m\left(1-d_{2}\right)}{n_{4}^{2}-n_{4}-\left(M^{2}+\frac{i \omega}{4}\right)}, \\
& d_{9}=\frac{A n_{5}\left(d_{3} m_{1}+d_{4} m_{3}\right)}{m_{5}\left\{n_{5}^{2}-n_{5}-\left(M^{2}+\frac{i \omega}{4}\right)\right\}} .
\end{aligned}
$$

With convention that real part of complex quantities has physical significance in the problem, from Eq. (12) the velocity, temperature and concentration profiles can be expressed in fluctuating part as

$$
F(y, t)=F_{0}(y)+\in\left[F_{r} \cos \omega t-F_{i} \sin \omega t\right],
$$

where $\quad F_{1}=F_{r}+i F_{i}$

Hence we can obtain the expressions for the transient velocity, temperature and concentration profiles for

$$
\omega t=\frac{\pi}{2} \text { as } F\left(y, \frac{\pi}{2 \omega}\right)=F_{0}(y)-\in F_{i} \text {. }
$$

Skin-friction: Knowing the velocity field, the expression for the skin-friction coefficient at the plate in the $x^{*}$-direction is given by:

$$
C_{f x}=\left(\frac{\partial u}{\partial y}\right)_{y=0} .
$$

Nusselt number: From the temperature field, the rate of heat transfer coefficient in terms of the Nusselt number $\mathrm{Nu}$ at the plate is given by

$$
N u=-\left(\frac{\partial \theta}{\partial y}\right)_{y=0} .
$$

Sherwood number: From the concentration field, the rate of mass transfer coefficient in terms of the Sherwood number $S h$ at the plate is given by

$$
S h=-\left(\frac{\partial \phi}{\partial y}\right)_{y=0} .
$$

\section{RESULTS AND DISCUSSION}

The numerical values of the transient velocity, transient temperature, coefficient of skin- friction, Nusselt number and Sherwood number are computed for different parameters like thermal Grashof number, mass
Grashof number, Hartmann number, Prandtl number, slip parameter, Schmidt number, frequency parameter, chemical reaction parameter and radiation parameter. To be realistic the two values of the Prandtl number Pras 0.71 and 7.00 are chosen to represent air and water respectively. The values of the Schmidt number $S c$ are chosen to represent the presence of various species, Carbon dioxide $(S c=0.94)$ and Oxygen $(S c=0.60)$. The values of other parameters are chosen arbitrarily

The transient velocity profiles are shown in Fig.1. It is observed from Fig.1 that velocity increases with the increase of thermal Grashof number, mass Grashof number, slip parameter and frequency of fluctuations, however, Hartmann number, Prandtl number, Schmidt number and radiation parameter have opposite effect on velocity profiles. It is also clear from Fig.1 that velocity decreases when there is no slip parameter.

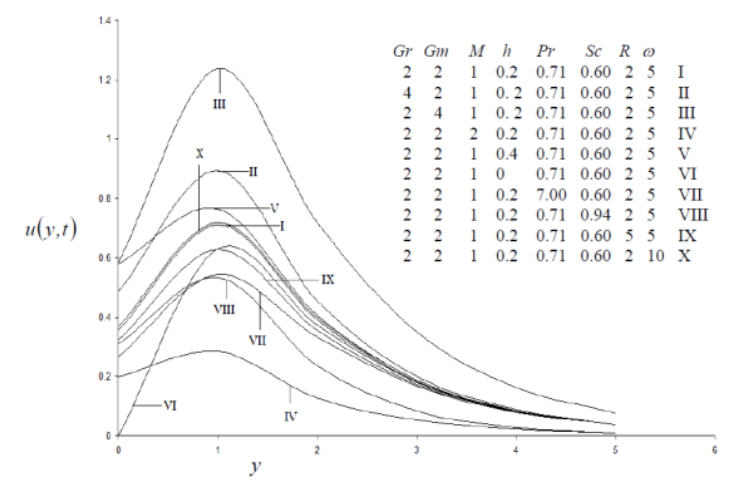

Fig. 1. Transient velocity for $\gamma=0.2, A=0.5$,

$$
\in=0.1, \omega t=\frac{\pi}{2} \text {. }
$$

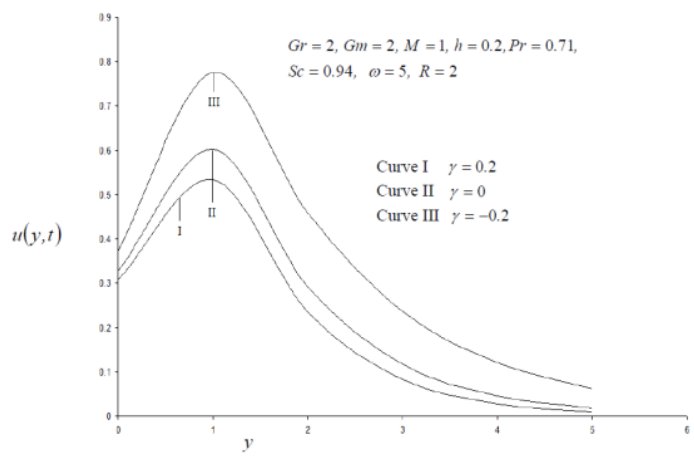

Fig. 2. Effect of chemical reactions on transient velocity for $\in=0.1, \omega t=\frac{\pi}{2}, A=0.5$.

Figure 2 shows the effect of chemical reaction on velocity profiles. It is clear from this figure that velocity decreases for destructive chemical reactions $(\gamma>0)$ and increases for generative chemical reactions $(\gamma<0)$. The numerical values of skin-friction coefficient at the plate are shown in Table 1 and Table 2. It is clear from these Tables that coefficient of skin-friction increases with the increase of thermal Grashof number, mass Grashof number and frequency of fluctuations, 
however, Hartmann number, Prandtl number, slip parameter, Schmidt number and radiation parameter have opposite effect on the coefficient of skin-friction. It is interesting to note that coefficient of skin-friction increases when there is no slip parameter. It is also observed from Table 2 that skin-friction coefficient decreases for destructive chemical reactions $(\gamma>0)$ and increases for generative chemical reactions $(\gamma<0)$.

Table 1 Values of skin-friction coefficient at the plate

when $\in=0.1, \omega t=\frac{\pi}{2}, A=0.5, S c=0.60, R=2$,
\begin{tabular}{cccccc}
$\gamma=0.2$, and $\omega=5$. \\
\hline$G r$ & $G m$ & $M$ & $h$ & $\operatorname{Pr}$ & $C_{f x}$ \\
\hline 2 & 2 & 1 & 0.2 & 0.71 & 1.7831 \\
4 & 2 & 1 & 0.2 & 0.71 & 2.4254 \\
2 & 4 & 1 & 0.2 & 0.71 & 2.9239 \\
2 & 2 & 2 & 0.2 & 0.71 & 0.9893 \\
2 & 2 & 1 & 0.4 & 0.71 & 1.4468 \\
2 & 2 & 1 & 0 & 0.71 & 2.3370 \\
2 & 2 & 1 & 0.2 & 7.00 & 1.3335 \\
\hline
\end{tabular}

Table 2 Values of skin-friction coefficient at the plate

when $\in=0.1, \omega t=\frac{\pi}{2}, A=0.5 \quad G r=2, G n$
\begin{tabular}{ccccc}
$M=1$ & $h=0.2$ and $\operatorname{Pr}=0.71$. \\
\hline$S c$ & $R$ & $\gamma$ & $\omega$ & $C_{f x}$ \\
\hline 0.60 & 2 & 0.2 & 5 & 1.7831 \\
0.94 & 2 & 0.2 & 5 & 1.5471 \\
0.60 & 5 & 0.2 & 5 & 1.6197 \\
0.94 & 2 & 0 & 5 & 1.6439 \\
0.94 & 2 & -0.2 & 5 & 1.8666 \\
0.60 & 2 & 0.2 & 10 & 1.7870 \\
\hline
\end{tabular}

The temperature profiles are presented in Fig. 3. From this figure it is observed that temperature decreases with the increasing radiation parameter and increases with the increasing frequency of fluctuations for $\operatorname{Pr}=0.71$ and $\operatorname{Pr}=7.00$.

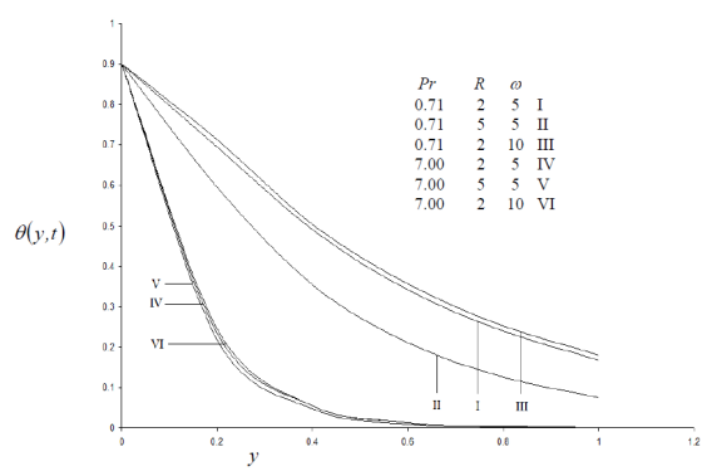

Fig. 3. Transient temperature for

$$
\in=0.1, \omega t=\frac{\pi}{2}, A=0.5 \text {. }
$$

The numerical values of Nusselt number $N u$ are presented in Table 3. It is clear from this Table that Nusselt number increases with the increasing radiation parameter and decreases with the increase of frequency of fluctuations for $\operatorname{Pr}=0.71$ and $\operatorname{Pr}=7.00$.
The concentration profiles are presented in Fig. 4. It is observed from this figure that concentration decreases with the increase of Schmidt number and increases with the increasing frequency of fluctuations. It is also clear from Fig. 4 that concentration decreases for destructive chemical reactions $(\gamma>0)$ and increases for generative chemical reactions $(\gamma<0)$.

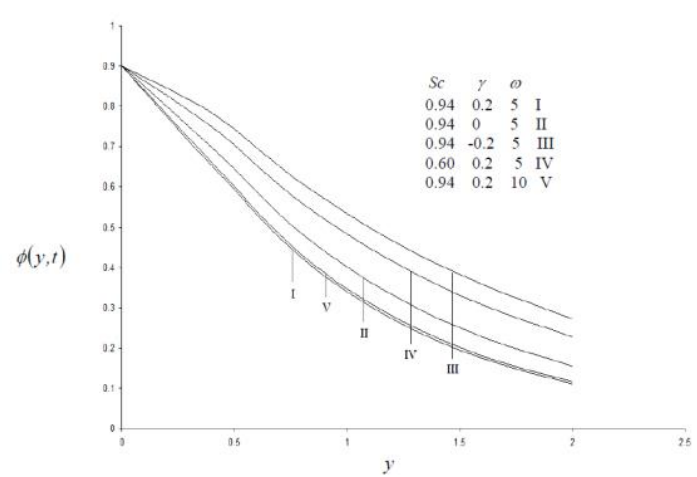

Fig. 4. Transient concentration for

$$
\in=0.1, \omega t=\frac{\pi}{2}, A=0.5 \text {. }
$$

Table 4 Values of Sherwood number $S h$ at the plate

\begin{tabular}{cccc}
\multicolumn{4}{c}{ when $\in=0.1, \omega t=\frac{\pi}{2}, A=0.5}$. \\
\hline$S c$ & $\gamma$ & $\omega$ & $N u$ \\
\hline 0.94 & 0.2 & 5 & 1.7875 \\
0.94 & 0 & 5 & 2.6005 \\
0.94 & -0.2 & 5 & 1.7602 \\
0.60 & 0.2 & 5 & 7.2104 \\
0.60 & 0.2 & 10 & 7.5890 \\
\hline
\end{tabular}

The numerical values of Sherwood number $S h$ are presented in Table 4. It is observed from this Table that Sherwood number increases for destructive chemical reactions $(\gamma>0)$ and decreases for generative chemical reactions $(\gamma<0)$. It is also clear from Table 4 that Sherwood number increases due to an increase in Schmidt number and decreases due to an increase in frequency of fluctuations.

\section{Conclusions}

The governing equations for fluctuating MHD free convective heat and mass transfer flow of radiating and reacting fluid past a vertical porous plate considering the effect of slip conditions were formulated. The resulting partial differential equations were transformed into a set of ordinary differential equations using twoterm series and solved in closed-form. Our results are found in good agreement with Sharma (2005) in the absence of chemical reaction, radiation and magnetic field effects. The conclusions of the study are as follows:

(1) The velocity increases significantly with increasing modified Grashoff number as compared to Hartmann number.

(2) Velocity and skin-friction coefficient increase for generative chemical reactions. However, destructive chemical reactions have opposite effect on velocity and skin-friction coefficient. 
K.D. Singh and R. Kumar / JAFM, Vol. 4, No. 4, pp. 101-106, 2011.

The Velocity decreases and Nusselt number increases with the increase of radiation parameter.

(4) Sherwood number increases and concentration decreases for destructive chemical reactions. However, generative chemical reactions have opposite effect on Sherwood number and concentration profiles.

\section{ACKNOWLEDGEMENT}

The authors are thankful to the learned referees for their valuable suggestions towards the improvement of the paper.

\section{REFERENCES}

Afify, A.A. (2004). Effects of radiation and chemical reaction on MHD free convective flow past a vertical isothermal cone. Canadian Journal of Physics 82, 447-458.

Anjalidevi, S.P. and R. Kandasamy (2000). Effects of chemical reaction heat and mass transfer on MHD flow past a semi-infinite plate. Z. Angew. Mathematics and Mechanics 80, 697-701.

Chambre, P.L. and J.D. Young (1958). On the diffusion of a chemically reactive species in a laminar boundary layer flow. Physics of Fluids 1, 48-54.

Chamkha, A. (2003). MHD flow of a uniformly stretched permeable surface in the presence of heat generation/absorption and chemical reaction. International Communication in Heat Mass Transfer 30, 413-422.

Das, U.N., R.K. Deka, and V.M. Soundalgekar (1994). Effects of mass transfer on flow past an impulsively started infinite vertical plate with constant heat flux and chemical reaction. Forsch. Ingenieurwes 60, 284-287.

Jain, N.C. and P. Gupta (2007). Unsteady magnetopolar free convection flow in slip-flow regime with variable permeability and constant heat flux. Journal of Energy Heat Mass Transfer 29, 227240.

Jothimani, S. and S.P. Anjalidevi (2001). MHD Couette flow with heat transfer and slip- flow effects in an inclined channel. Journal of Mathematics 43, 4762 .

Kandasamy, R., K. Periasamy and K.K. Sivagnana Prabhu (2005). Effects of chemical reactions heat and mass transfer along a wedge with heat source in the presence of suction/injection. International Journal of Heat Mass Transfer 48, 1388-1393.

Loganthan, P., T. Kulandaivel and R. Muthucumaraswami (2008). First order chemical reaction on moving semi-infinite vertical plate in the presence of optically thin gray gas.
International Journal of Applied Mathematics and Mechanics 4(5), 26-41.

Mansour, M.A., N.F. El-Anssary and A.M. Aly (2008). Effects of chemical reaction and viscous dissipation on MHD natural convection flows saturated in porous media. International Journal of Applied Mathematics and Mechanics 4(2), 60-76.

Mansour, M.A., R.A. Mohamed, M.M. Abd-Elaziz and S.E. Ahmed (2007). Fluctuating thermal and mass diffusion on unsteady MHD convection of a micropolar fluid through a porous medium past a vertical plate slip-flow regime. International Journal of Applied Mathematics and Mechanics 3(3), 99-117.

Muthucumaraswamy, R. and P. Ganesan (2001). First order chemical reaction on flow past an impulsively started vertical plate with uniform heat and mass flux. Acta Mechanica 147, 45-57.

Raptis, A. and C. Perdikis (2006). Viscous flow over a non-linearly stretching sheet in the presence of a chemical reaction and magnetic field. International Journal of Non-Linear Mechanics $41,527-529$.

Raptis, A. and C. Perdikis (2006). Viscous flow over a non-linearly stretching sheet in the presence of a chemical reaction and magnetic field. Inernational Journal of Non-Linear Mechanics 41, 527-529.

Raptis, A. and C. Perdikis, (2003). Thermal radiation of an optically thin gray gas. International Journal of Applied Mechanics and Engineering 8, 131-134.

Sharma, B.K., R.C. Chaudhary and M. Agarwal (2008). Radiation effect on steady free convective flow along a uniform moving vertical porous plate in presence of heat source/sink and transverse magnetic field. Bulletin of Calcutta Mathematical Society 100(5), 529-538.

Sharma, P.K. (2005). Fluctuating thermal and mass diffusion on unsteady free convection flow past a vertical plate in slip-flow regime. Latin American Applied Research 35, 313-319.

Sharma, P.K. and B.K. Sharma (2004). Influence of variable suction on unsteady free convective flow from a vertical plate and heat transfer in slip-flow regime. Ganita Sandesh 18, 55-62.

Sharma, P.K. and R.C. Chaudhary (2003). Effect of variable suction on transient free convection viscous incompressible flow past a vertical plate with periodic temperature variation in slip-flow regime. Journal of Engineering Research 8, 33-38.

Takhar, H.S., A.J. Chamkha and G. Nath (2000). Flow and mass transfer on a stretching sheet with a magnetic field and chemically reactive species. International Journal of Engineering and Science 38, 1303-1306. 